\title{
Factors That Influence Females' Intention towards Breast Cancer Early Diagnosis
}

\author{
Jing Huey Chin $^{1} \&$ Shaheen Mansori ${ }^{2}$ \\ ${ }^{1}$ Malaysia University of Science and Technology, Selangor, Malaysia \\ ${ }^{2}$ Malaysia University of Science and Technology, Selangor, Malaysia \\ Correspondence: Jing Huey Chin, Malaysia University of Science and Technology, 12, Jalan PJU 5/5, Kota \\ Damansara, 47810 Petaling Jaya, Selangor, Malaysia. Tel: 60-102-726-730. E-mail: victoria.chin44@ gmail.com
}

\author{
Received: October 9, 2018 Accepted: October 26, 2018 Online Published: November 28, 2018 \\ doi:10.5539/cco.v7n2p43 URL: https://doi.org/10.5539/cco.v7n2p43
}

\begin{abstract}
Despite the advanced medical technology nowadays, breast cancer incidence rate is still increasing worldwide. This is due to females lack of knowledge and awareness about the breast screening. Therefore, the objective of this study is to explore the factors that influence females' intention towards breast cancer early diagnosis with health belief model and provide practical recommendations. To evaluate the proposed hypotheses in this study, 600 self-administrated questionnaires were distributed to Malaysian female who is 18 years old and above with the usage of non-probable sampling approach (convenience sampling approach). Given that, the findings demonstrate perceived barriers has the greatest impact towards females' breast cancer early diagnosis intention, followed by perceived severity and perceived susceptibility. The contribution of this study is to evaluate the relationships between perceived severity, perceived susceptibility and perceived barriers towards females' breast screening intention with the mediating variable of attitude. To support this, health believe model and theory of planned behaviour are employed in this research.
\end{abstract}

Keywords attitude, awareness, breast cancer early diagnosis, health belief model, intention, knowledge, theory of planned behaviour

\section{Introduction}

Breast cancer, a preventive fatal disease, is one of the top five highest cancer killers among females. Statistical studies reveal that 252000 females were diagnosed in year 2017 and it is expected to increase to 266,120 (5.6\%) in year 2018 (DeSantis, Ma, Goding Sauer, Newman, \& Jemal, 2017). In addition, researches report that overall breast cancer incidence rates increase at the average of $1.7 \%$ annually in the past decade (National cancer institute, 2018). Conversely, 40920 breast cancer deaths are expected to occur in year 2018. Supported by empirical studies, breast cancer mortality rate decreased by almost $40 \%$ in the past 20 years due to the advanced medical technology (Susan, 2015; Tarkowska, Mrotek, \& Gastecka, 2017; Zhang, 2015). However, breast cancer incidence has no sound reason for the marked increase rate.

Given that, many factors have been examined and evaluated such as lack of knowledge and awareness, insufficient of health information, social marketing campaign failure, cost of health care and many more (Kirca, Tuzcu, \& Gozum, 2018; Mar, Sam, \& Wilson, 2018; Osina, 2017a; Rainey et al., 2018). Also, psychosocial factors for example, fear of breast screening results, ashamed of own-self unhealthy condition have further contributed to the late stage breast screening (Gupta et al., 2018; Santana et al., 2018). This explains the impact of the marked increase breast cancer incidence rate globally.

Afflicted with the increasing trend of breast cancer incidence rate, limited studies emphasise on the factors that influence females' intention towards breast cancer early diagnosis (Darvishpour, Vajari, \& Noroozi, 2018; Venturini, 2016; Wang, Hsu, Wang, Huang, \& Hsu, 2014). Therefore, the purpose of this research is to provide a literature review platform for the scholars to have more intensive insights in understanding females' behavioural change. In term of contribution to health practitioners, this study seek to propose practical recommendations to increase females' breast cancer prevention awareness using health belief model and social marketing approach (Bastami, Zamani-alavijeh, Mostafavi, Almasian, \& Hydari, 2018; Farajzadegan et al., 2016; Koh, Choi, \& Cho, 2016; Schillinger, Tran, \& Fine, 2018). This research structure begins with the grounded theory of health belief 
model and theory of planned behaviour followed by the application of social marketing approach to develop a conceptual framework in the context of females' intention towards breast cancer early diagnosis.

\section{Literature Review}

\subsection{Health Belief Model}

Since the early incarnation of health belief model (HBM), this psychological health behaviour change model has been widely used in health-related researches to understand and predict people's beliefs and attitude towards a specific health problem (Abu-Saad Huijer \& Abboud, 2012; Cal \& Bahar, 2018; Koh et al., 2016). HBM was introduced in 1950s by Irwin M. Rosenstock, Godfrey M. Hochbaum and their team members during the tuberculosis screening research. Most recently, many health experts have been employing this model to predict patients' behavioural tendency and cognition responses, deliver health information, motivate health behavioural change and provide innovative ideas to enhance social marketing campaigns (Mattson \& Basu, 2010; Spotswood, French, Tapp, \& Stead, 2012).

Through the lens of HBM, it consists of six core constructs: perceived severity, perceived susceptibility, perceived benefits, perceived barriers, cues to action and self-efficacy (Didarloo, Nabilou, \& Khalkhali, 2017; Yilmaz \& Durmus, 2016). Given that, this research highlights the three constructs of perceived severity, perceived susceptibility and perceived barriers towards females' intention on breast screening. Firstly, perceived severity is a person's perception towards the seriousness of a health problem and its possible outcome (Ersin, Gözükara, Polat, Erçetin, \& Bozkurt, 2015; Kissal, Kartal, \& Cetin, 2017). To clarify, perceived severity includes life-threatening disease, disability, long-term pain and treatment required, unable to go for work and many more.

Utilising HBM, breast cancer is a preventive fatal disease which has great negative impact towards females (Chin \& Mansori, 2018; Farajzadegan et al., 2016; Osina, 2017b). If the female perceives that developing into breast cancer could bring her severe consequences like financial issue on her family, adversely affect her routine life, temporary side-effects, severe breast pain, these possible outcomes will shape her attitude (Bethesda, 1993; Morrison, Hodgson, \& Haites, 2002). In theory of planned behaviour (TPB), attitude is a person's subjective assessment towards the value from executing the intended behaviour. If the benefits overweigh the costs incurred, the person will evaluate this intended behaviour as favourable (Mazloomy-mahmoodabad, Navabi, \& Ahmadi, 2017; Rahmati-Najarkolaei et al., 2017). In relation to this, if the female believes that breast screening could reduce the perceived severity on her, it will shape towards her attitude to get breast screened.

Perceived susceptibility refers to the possible risk of a person developing into a disease. With high level of perceived susceptibility, the person is more likely to engage into a suggested behaviour to prevent the disease from occurring (Abolfotouh et al., 2015; DeSantis, Ma, Sauer, Newman, \& Jermal, 2017; M. A. Smith, Conway-Phillips, \& Francois-Blue, 2016). As opposed, if a person believes that he/she has low level of perceived susceptibility, it might lead the person to engage into unhealthy behaviour. Reflecting in breast cancer early diagnosis, if the female has family history of breast cancer, she might have high risk developing into breast cancer as well (Jamei, Ostovar, \& Javadzade, 2017; Sun, Legood, Sadique, dos-Santos-Silva, \& Yang, 2018; Torbaghan, Farmanfarma, Moghaddam, \& Zarei, 2014). In subjective norm by TPB, supported by the family members, relatives and friends due to the female's inherent risk factor, high perceived susceptibility will shape as her perception and attitude towards breast cancer and thus, this will lead to the higher likelihood of breast cancer early diagnosis (Darvishpour et al., 2018; DeSantis, Ma, Goding Sauer, et al., 2017; Venturini, 2016).

Based on HBM, perceived barriers is termed as the obstacles that refrain a person from executing the suggested behaviour (Kissal et al., 2017; Koh et al., 2016; Wang et al., 2014). Given the example, misconception about diagnosis, cultural beliefs, inconvenience, pricy health care services are part of the contributors to the perceived barriers. Hence, perceived barriers should be reduced to facilitate the females to go for breast screening (Abu-Saad Huijer \& Abboud, 2012; Darvishpour et al., 2018; Didarloo et al., 2017). To further illustrate, if the health practitioner explains the procedure of the breast screening to the patient, sharing with her about the current affordable health packages, ease her with breast screening appointment during health care consultation, these motivations will reduce the patient's level of perceived barriers (Farajzadegan et al., 2016; Osina, 2017b). Subsequently, the female will assess it as low perceived barriers, and intuitively, the level of attitude towards breast cancer early diagnosis will increase. Summarised briefly, to further understand the relationships between perceived severity, perceived susceptibility, perceived barriers and attitude towards breast cancer early diagnosis, three hypotheses were conducted as follows:

Hypothesis 1: There is a relationship between perceived severity and attitude towards breast cancer early diagnosis. 
Hypothesis 2: There is a relationship between perceived susceptibility and attitude towards breast cancer early diagnosis.

Hypothesis 3: There is a relationship between perceived barriers and attitude towards breast cancer early diagnosis.

\subsection{Theory of Planned Behaviour}

According to theory of planned behaviour (TPB), this theory encompasses three main constructs: attitude towards the behaviour, subjective norm and perceived behavioural control (Klehe, 2018; Peechapol, Na-songkhla, Sujiva, \& Luangsodsai, 2018; Radovanovic \& Rus-Makovec, 2018; Seow, Choong, Moorthy, \& Chan, 2017). In line with this study, attitude is able to predict a person's intention towards a specific behaviour. It is described as a person's subjective evaluation or past experience towards an intended behaviour based on the expected outcome from the particular behaviour (Erten, 2018; Lang, 2018). Likewise, TPB has been widely applied on health related programs/ interventions to study a person's cognition response and to provide an intensive understanding of the reasons why a person performs or fails to perform that specific behavioural tendency (Kopelowicz et al., 2015; Mutua, Pertet, \& Otieno, 2017; Narmawan, Syahrul, \& Erika, 2018). Empirical studies reviewed that, a person are likely to engage into a particular behaviour only if, he/she perceives it as favourable (positive outcome expectancy) and vice versa (Kalolo \& Kibusi, 2015; Leske, Strodl, \& Hou, 2017; Mtenga, Exavery, Kakoko, \& Geubbels, 2015).

In present study, a female's attitude is the crucial key to predict her intention towards breast cancer early diagnosis (Ke, Yang, \& Jing, 2018; Setyowibowo et al., 2018; A. Smith, Mullooly, Murphy, Barron, \& Bennett, 2018). Based on the female's beliefs, if she perceives that getting breast screened will help her to reduce the negative consequences that affect her routine life, minimise the risk of developing into breast cancer without undue effort, affordable price and proper referral from health care centre, the female is likely to shape this screening habit as favourable attitude, and subsequently, it will increase the likelihood of the intended breast screening. Given that, to test this relationship between attitude and intention, a proposed hypothesis was designed:

Hypothesis 4: There is a relationship between attitude and intention towards breast cancer early diagnosis.

\subsection{Mediation Effect}

A mediating variable (mediator) is a variable which causes mediation between an independent variable and dependent variable. To further illustrate, mediating variable means that its existence will cause significance on the relationships between the variables and thus, affect the outcome (Geuens \& De Pelsmacker, 2017; Jezak, 2017; Ogbuanya \& Chukwuedo, 2016). By and large, it is therefore mediating variable provides great value by exploring the mechanism that underlies between the variables. Yet, inconsistent findings have been found with the limitation in utilising attitude as a predictor for the health promoting behaviour and it remains largely unexplored (Darvishpour et al., 2018; DeSantis, Ma, Goding Sauer, et al., 2017; Venturini, 2016).

As such, in this research, mediation analysis was employed to further understand the factors that influence females' intention towards breast cancer early diagnosis with the component of attitude by TPB as mediating variable. Thus, to study the mediation effect between the variables and intention, three hypotheses were conducted:

Hypothesis 5: Attitude mediates the relationship between perceived severity and intention.

Hypothesis 6: Attitude mediates the relationship between perceived susceptibility and intention.

Hypothesis 7: Attitude mediates the relationship between perceived barriers and intention.

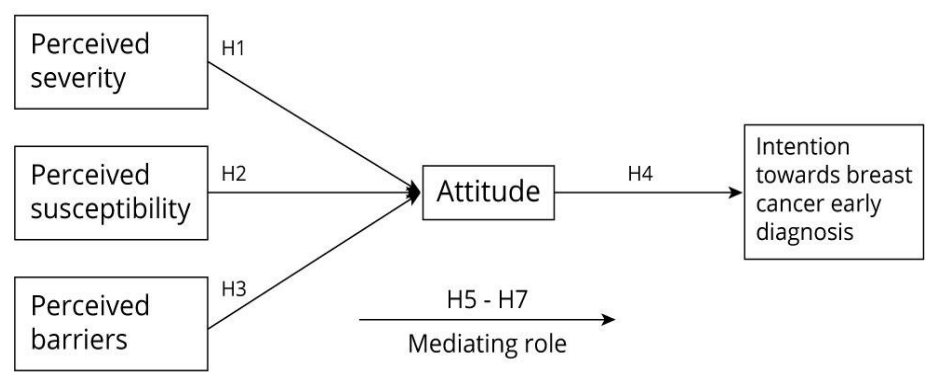

Figure 1. Health Belief Model On Intention Towards Breast Cancer Early Diagnosis 


\section{Research Methodology}

Drawing from this research, the population selected is Malaysian female who is 18 years old and above. The data collection was conduct at public transportation hubs such as Kuala Lumpur International Airport, Kuala Lumpur Centre, Terminal Bersepadu Selatan (main northern zone bus centre Malaysia) and other bus stations. Next, 600 self-administrated questionnaires were distributed throughout all the states in Peninsular Malaysia, Sabah and Sarawak using non-probable sampling approach (convenience sampling approach).

Consistent with this explanation, the questionnaire consists of two sections: section A, questions regarding perceived severity, perceived susceptibility, perceived barriers, attitude and intention; section B is participant's demographic information like age, marital status, educational level and hometown state. In order to have better accuracy and understanding, the questionnaire was designed into international English language.

\subsection{Data Analysis}

From the returned questionnaires, 507 of total samples were finalised for data analysis after filtering some missing values and the incomplete questionnaires (refer Appendix A). According to Table 1, one third of the respondents are between 18-30 years old (35.9\%). As for the age between 31- 40 and 41- 50, both stand similar percentage $(23.7 \%$ and $23.5 \%$ respectively). In addition, marital status shows an approximation of $63 \%$ participants are married and $32.7 \%$ are still single. Furthermore, Table 1 also demonstrates that more than half of the participants are Muslims (56.8\%) whilst Buddhism stands for $22.7 \%$, followed by Christianity (11.4\%).

Table 1. Demographic Information

\begin{tabular}{lllll}
\hline Characteristics & & Frequency & Percent & Cumulative percent \\
\hline Age & $18-30$ & 182 & 35.9 & 35.9 \\
& $31-40$ & 120 & 23.7 & 59.6 \\
& $41-50$ & 119 & 23.5 & 83.0 \\
& Above 50 & 86 & 17.0 & 100.0 \\
& Total & 507 & 100.0 & \\
\hline Marital Status & Single & 166 & 32.7 & 32.7 \\
& Married & 320 & 63.1 & 95.9 \\
& Other & 21 & 4.1 & 100.0 \\
& Total & 507 & 100.0 & \\
\hline \multirow{2}{*}{ Religion } & Islam & 288 & 56.8 & 56.8 \\
& Buddhism & 115 & 22.7 & 79.5 \\
& Christianity & 58 & 11.4 & 90.9 \\
& Hinduism & 21 & 4.1 & 95.1 \\
& Other & 25 & 4.9 & 100.0 \\
& Total & 507 & 100.0 & \\
\hline
\end{tabular}

This reliability and validity analysis was based on the females' intention of breast cancer early diagnosis scale, and it is crucial to evaluate the good fit of this model. In accordance, the developed measurement model is considered model fit within the reliability and validity acceptable range (refers Table 2). To further clarify, the presented table consists of four components: factor loading, average variance extracted (AVE), composite reliability (CR) and Cronbach's Alpha (CA).

Firstly, factor loading is considered acceptable if it is greater than 0.5 , and the values below report the range of factor loadings is between 0.629- 0.897. As opposed, AVE posits the value from 0.531- 0.726 (more than 0.5) whilst CR possesses the value between 0.848- 0.919 and relatively, evidence the level of acceptance (greater than $0.7)$. Subsequently, CA shows that all values are more than 0.7 (0.792- 0.890$)$. It is therefore concluded that the reliability and validity of this model is high and within the level of acceptance. 
Table 2. Reliability and Validity Analysis

\begin{tabular}{|c|c|c|c|c|}
\hline Dimension & $\begin{array}{l}\text { Factor } \\
\text { loading }\end{array}$ & $\begin{array}{l}\text { Average variance } \\
\text { extracted (AVE) }\end{array}$ & $\begin{array}{l}\text { Composite } \\
\text { reliability (CR) }\end{array}$ & $\begin{array}{l}\text { Cronbach's } \\
\text { Alpha (CA) }\end{array}$ \\
\hline \multicolumn{5}{|c|}{ Perceived severity } \\
\hline S1 & 0.736 & 0.575 & 0.870 & 0.825 \\
\hline $\mathrm{S} 2$ & 0.655 & & & \\
\hline S3 & 0.861 & & & \\
\hline S4 & 0.699 & & & \\
\hline S5 & 0.822 & & & \\
\hline \multicolumn{5}{|c|}{ Perceived susceptibility } \\
\hline $\mathrm{P} 1$ & 0.728 & 0.638 & 0.876 & 0.817 \\
\hline $\mathrm{P} 2$ & 0.837 & & & \\
\hline P3 & 0.784 & & & \\
\hline $\mathrm{P} 4$ & 0.841 & & & \\
\hline \multicolumn{5}{|c|}{ Perceived barriers } \\
\hline B1 & 0.856 & 0.726 & 0.914 & 0.874 \\
\hline B2 & 0.854 & & & \\
\hline B3 & 0.887 & & & \\
\hline B4 & 0.808 & & & \\
\hline \multicolumn{5}{|l|}{ Attitude } \\
\hline A1 & 0.812 & 0.531 & 0.848 & 0.792 \\
\hline A2 & 0.825 & & & \\
\hline A3 & 0.629 & & & \\
\hline A4 & 0.719 & & & \\
\hline A5 & 0.634 & & & \\
\hline \multicolumn{5}{|l|}{ Intention } \\
\hline I1 & 0.844 & 0.695 & 0.919 & 0.890 \\
\hline $\mathrm{I} 2$ & 0.734 & & & \\
\hline $\mathrm{I} 3$ & 0.813 & & & \\
\hline I4 & 0.870 & & & \\
\hline I5 & 0.897 & & & \\
\hline
\end{tabular}

To our best knowledge, the structural model below (Figure 2) was applied to justify the mediation effect of attitude. The initial model includes three independent variables: perceived severity, perceived susceptibility and perceived barriers towards breast cancer early diagnosis intention with attitude, being as the mediating variable.

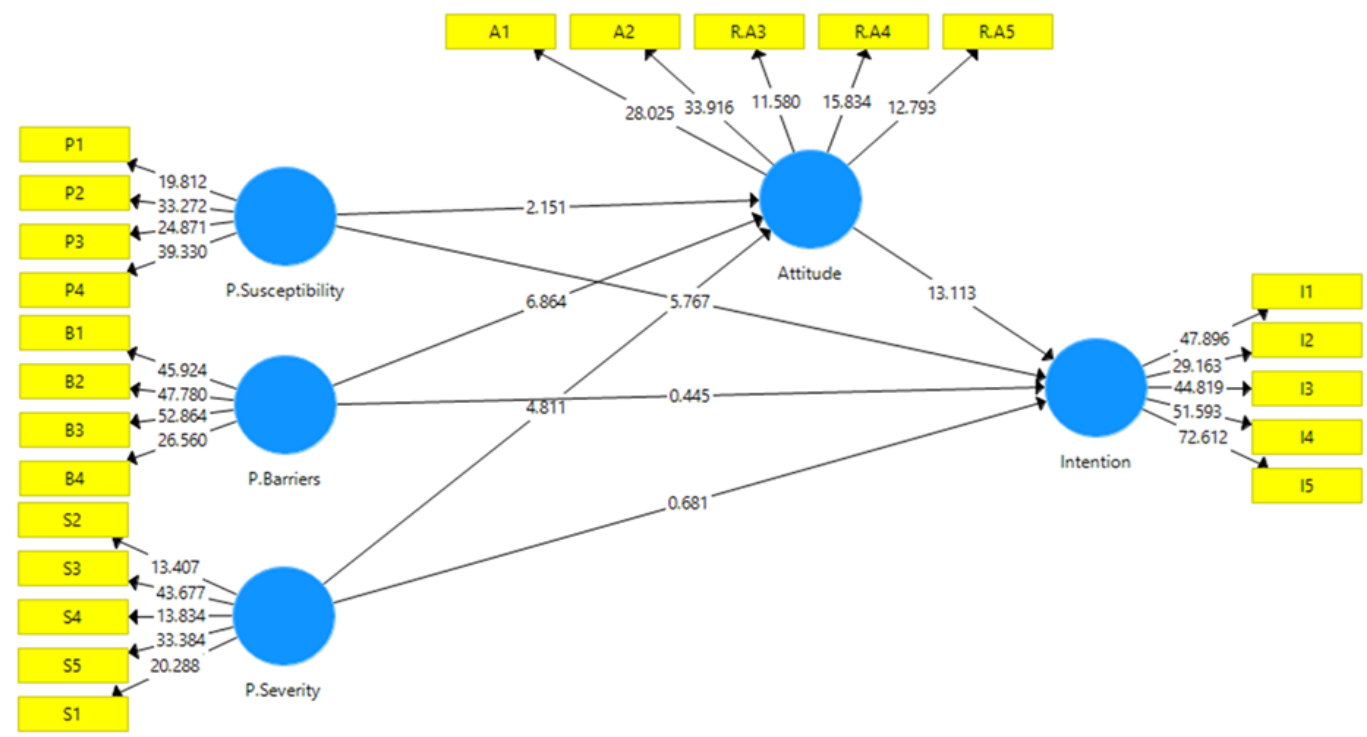

Figure 2. Path Model with Attitude as Mediating Variable 
Drawing from Table 3 below, perceived severity shows a direct significant relationship towards attitude and subsequently, it is supported $(H I)(\beta=0.224$, p-value $=0.000)$. The hypothesis illustrates that the impact of the breast cancer consequences will form females' attitude towards breast cancer early diagnosis. In relation to perceived susceptibility, $H 2$ shows a significant positive relationship with $\beta=0.112$, p-value $=0.016$ (supported). This indicates that the higher level of perceived susceptibility, the higher level of attitude towards breast cancer early diagnosis.

The hypothesis testing also demonstrates that there is a significant negative relationship between perceived barriers and attitude $(H 3)(\beta=-0.342$, p-value $=0.000)$. Given that, it represents the lower level of perceived barriers, the higher level of females' attitude towards breast cancer early diagnosis (supported). In $H 4$, there is a direct significant relationship between attitude towards intention with the value of $\beta=0.537$, p-value $=0.000$. In brief, this justifies the higher level of attitude, the higher level of females' intention towards breast cancer early diagnosis and thus, it is supported.

Along in this table, attitude's $\mathrm{R}^{2}$ is $17.8 \%(0.178)$ whilst intention's $\mathrm{R}^{2}$ is $33.6 \%(0.336)$. The attitude's $\mathrm{R}^{2}$ suppresses that $17.8 \%$ variance of the attitude can be explained by the independent variables and $33.6 \%$ variance of the intention towards breast cancer early diagnosis can be explained by attitude.

Table 3. Hypothesis Testing

\begin{tabular}{llllll}
\hline Hypothesis (Direct relationship) & Sample mean $\beta$ & Standard deviation & T statistics & P values & Significant \\
\hline H1: Perceived severity $\rightarrow$ Attitude & 0.224 & 0.046 & 4.811 & 0.000 & Yes \\
H2: Perceived susceptibility $\rightarrow$ Attitude & 0.112 & 0.050 & 2.151 & 0.016 & Yes \\
H3: Perceived barriers $\rightarrow$ Attitude & -0.342 & 0.049 & 6.864 & 0.000 & Yes \\
H4: Attitude $\rightarrow$ Intention & 0.537 & 0.041 & 13.113 & 0.000 & Yes \\
\hline Attitude's R-Square $=0.178$ & & & & & \\
Intention's R-Square $=0.336$ & & & & & \\
\hline
\end{tabular}

To evaluate the mediation effect of attitude in this study, bootstrapping method was employed on the relationships between perceived severity, perceived susceptibility and perceived barriers towards females' breast cancer early diagnosis intention.

Drawing from the total indirect effect category (Table 4), attitude shows its mediation effect on all three hypotheses. To further clarify, both relationships between perceived severity and perceived barriers towards intention with attitude as the mediating variable, validate that there is a significant relationship with full mediation effect $(\beta=0.120, p$-value $=0.000 ; \beta=-0.183, p$-value $=0.000)$. To further explain (in Path $\left.c^{\prime}\right), H 5$ exhibits the insignificant relationship (full mediation) with the value of $\beta=0.033$, p-value $=0.248$ and $H 7$ also reveals the full mediation role with the support of $\beta=0.016, p$-value $=0.328$. On the different note, there is a significant relationship between perceived susceptibility and intention with partial mediation effect, showing with the significance of $\beta=0.061$, p-value $=0.020$. Given in $H 6$, it demonstrates a significant relationship between the variables $(\beta=0.249$, $p$-value $=0.000)$ and thus, indicates the partial mediation role.

Table 4. Test of Total Effect Using Bootstrapping

\begin{tabular}{llllll}
\hline \multicolumn{1}{c}{ Paths } & Sample mean & Standard deviation & T statistics & P values & Significant \\
\hline Path c'(with mediator) & & & & & \\
\hline H5: Perceived severity $\rightarrow$ Intention & 0.033 & 0.045 & 0.681 & 0.248 & No \\
H6: Perceived susceptibility $\rightarrow$ Intention & 0.249 & 0.043 & 5.767 & 0.000 & Yes \\
H7: Perceived barriers $\rightarrow$ Intention & 0.016 & 0.044 & 0.445 & 0.328 & No \\
\hline Total indirect effect & & & & & \\
\hline Perceived severity $\rightarrow$ Intention & 0.120 & 0.026 & 4.528 & 0.000 & Yes- Full mediation \\
Perceived susceptibility $\rightarrow$ Intention & 0.061 & 0.028 & 2.048 & 0.020 & Yes- Partial mediation \\
Perceived barriers $\rightarrow$ Intention & -0.183 & 0.030 & 6.142 & 0.000 & Yes- Full mediation \\
\hline
\end{tabular}

\section{Findings and Discussion}

By and large, the purpose of data analysis is to evaluate the relationships between the independent variables and intention with the inclusion of mediating variable, attitude. According to the findings, all perceived severity, perceived susceptibility and perceived barriers reveal significant influences towards females' breast cancer early diagnosis attitude and intention. In line with these, perceived barriers (H3) has the highest impact towards breast 
screening attitude and it is followed by perceived severity $(\mathrm{H} 1)$. Relatively, perceived susceptibility $(\mathrm{H} 2)$ holds the third ranking in influencing females' breast cancer early diagnosis.

Being the main contributions to the females' behavioural change, breast cancer awareness could be facilitated by providing several social marketing strategies (Bastami et al., 2018; Gordon, Russell-Bennett, \& Lefebvre, 2016; Schillinger et al., 2018). Associated with perceived barriers, clinical physicians could call up the patients to remind them of annually clinical breast examinations and ease them by setting up a check-up appointment (Ersin et al., 2015; Farajzadegan et al., 2016). The government could reinforce majority of the clinics including rural areas to provide breast screening tests. Also, government health sector and policy makers could reinforce breast screening as a preliminary step for females prior to purchase health insurance or as an obligation to get breast screened when they reach certain ages.

Mentioned in the previous statement, perceived severity towards females' breast screening attitude is probably due to the females do not see breast cancer consequences as severe. Given the example, although the cigarette package is printed with severe negative impact of smoking, people still choose to ignore the warning sign on the package and remain purchasing it (Flores et al., 2018; Garey et al., 2018; Kovacs, Palmer, Correa, \& Brandon, 2018; Pettey \& Aubry, 2018). To counter the perceived severity, health care consultants could explain the consequences of the late stage breast screening to the females for example, warm reminding them that their health could indirectly involve their family members like cash flows/financial problem, children emotional development upon accepting the incidence happened and even their relationships with the husband. In line with this, the message could be delivered through clinical posters, brochures, mailings through health promotion subscriptions and public health campaigns (Abolfotouh et al., 2015; Chin \& Mansori, 2018; Osina, 2017b).

As for perceived susceptibility, health practitioners should highlight in the different direction which the patients will have more respond tendency into it. Given the example, by telling them the probability of the risk in getting breast cancer being as a female, informing them about the increase chances of developing into breast cancer when they start aging during breast cancer awareness campaigns and body check-up consultations. Besides that, breast cancer symptoms could be always questioned to the patients with simpler wordings to ease their understanding and also to remind their current health conditions such as "Do you have random tingling feeling?", "Do you find any unusual bump?", "Do you feel your breast turning dense?" and many more.

Breast cancer-related knowledge could be implemented indirectly with an informal method during consultations such as informing the patients about the possibility of passing the abnormal gene mutations (BRCA1 and BRCA2) to their children, and thus, encourage the patients to be the role models for their children by cultivating a regular breast screening habit. To facilitate, physical test, breast self-examination (BSE), types of breast screening test including genetic test could be introduced, explained or performed during social marketing and breast cancer awareness campaigns. Simply put, it is proposed that health practitioners could provide adequate information about breast cancer content for the patients in order to deliver the awareness message and conceive it in their notions. This could be achieved by converting this message spreading as a public health education using education and social media platforms for example, at the beginning of the movie, during student events and activities, social sport activities and many more (Bakan, 2016; Gordon, Russell-Bennett, \& Lefebvre, 2016; Venturini, 2016).

Overall, view in this point and it becomes clearer that, appropriate health message delivery and social marketing approach are influential tools to implement health-promoting behaviour (Bastami et al., 2018; Schillinger et al., 2018). The reason explains that, throughout the support of health belief model and theory of planned behaviour, females' attitude and intention towards breast cancer early diagnosis could be predicted (Krisjanous, 2014; McAuley, 2014; Reynolds, Subašić, \& Tindall, 2015).

In essence, this research offers imperative recommendations for the health practitioners and professionals to understand the patients' decision making processes and reactions through the effective usage of behavioural change theories and breast cancer-related communication. The reason is that, despite the advanced medical technology, females remain delay in seeking for the assistance of health experts/doctors even when the breast cancer symptoms occur. To accomplish this, more intensive health related literature review is the first crucial step to provide a springboard for health literacy to develop a series of breast cancer knowledge and awareness among females and subsequently, to build a more integrated conceptual framework for females' breast cancer early diagnosis.

\section{Limitations for Further Research}

Every research comes with limitations, and there is no exemption for this research. Drawing from data analysis, non-probable sampling approach (convenience sampling approach) was utilised in this study and consequently, 
the results from these data should be generalized due to the limitation of the method used. Furthermore, the $\mathrm{R}^{2}$ of the attitude and intention may not represent the absolute predictor for the dependent variable. This is because insignificant variables may also increase $\mathrm{R}^{2}$ 's value and hence, the scholars could not tell the level of importance of the independent variables by merely depending on the value of $\mathrm{R}^{2}$. However, this limitation could be reduced by choosing the appropriate selection procedures in the future research.

On the other hand, quantitative approach (deductive approach) was selected and given that, vague explanations in the data report due to the inherent numeric form of the approach. This could limit the health practitioners and scholars in fully understanding the exact message delivery. Therefore, it is suggested that mixture of quantitative and qualitative approach (inductive approach- interviews and focus group) should be adopted for future breast cancer early diagnosis research.

\section{References}

Abolfotouh, M. A., BaniMustafa, A. A., Mahfouz, A. A., Al-Assiri, M. H., Al-Juhani, A. F., \& Alaskar, A. S. (2015). Using the health belief model to predict breast self examination among Saudi women. BMC Public Health, 15(1), 1163. https://doi.org/10.1186/s12889-015-2510-y

Abu-Saad, Huijer, H., \& Abboud, S. (2012). Health-related quality of life among breast cancer patients in Lebanon. European Journal of Oncology Nursing, 16(5), 491-497. https://doi.org/10.1016/j.ejon.2011.11.003

Bakan, J. (2016). Social marketing: thoughts from an empathetic outsider. Journal of Marketing Management, 32(11-12), 1183-1189. https://doi.org/10.1080/0267257X.2016.1171035

Bastami, F., Zamani-alavijeh, F., Mostafavi, F., Almasian, M., \& Hydari, M. (2018). Formative Research on a Social Marketing Campaign to Promote the Consumption of Healthy Breakfast and Snacks: A Qualitative Study. International Journal of Pediatrics-Mashhad, 6(3), 7353-7367. https://doi.org/10.22038/ijp.2017.26699.2301

Bethesda. (1993). President's Cancer Panel Special Commission on Breast Cancer [microform] : screening and early detection: development of new technologies for detection and diagnosis : Miami, Florida, Thursday, March 18, 1993, and Friday, March 19, 1993. [Bethesda, MD] : National Institutes of Health, National Cancer Institute, 1993. Retrieved from

http://ezproxy.sunway.edu.my/login?url=http://search.ebscohost.com/login.aspx?direct=true\&db=edsgpr\&A $\mathrm{N}=$ edsgpr.000416516\&site $=$ eds-live \&scope $=$ site

Cal, A., \& Bahar, Z. (2018). Use of the Health Belief Model in the prevention of lymphedema after breast surgery. Prog Health Sci, 8(1), 176-181. https://doi.org/10.5604/01.3001.0012.1115

Chin, J. H., \& Mansori, S. (2018). Social Marketing and Public Health: A Literature Review. Journal of Marketing Management and Consumer Behavior, 2(2), 48-66.

Darvishpour, A., Vajari, S. M., \& Noroozi, S. (2018). Can Health Belief Model Predict Breast Cancer Screening Behaviors? Open Access Macedonian Journal of Medical Sciences, 6(5), 949-953. https://doi.org/10.3889/oamjms.2018.183

DeSantis, C. E., Ma, J., Goding Sauer, A., Newman, L. A., \& Jemal, A. (2017). Breast cancer statistics, 2017, racial disparity in mortality by state. CA: A Cancer Journal for Clinicians, 67(6), 439-448. https://doi.org/10.3322/caac.21412

DeSantis, C. E., Ma, J., Sauer, A. G., Newman, L. A., \& Jermal, A. (2017). Breast Cancer Statistics , 2017 , Racial Disparity in Mortality by State. A Cancer Journal for Clinicians, 67(6), 439-448. https://doi.org/10.3322/caac.21412.

Didarloo, A., Nabilou, B., \& Khalkhali, H. R. (2017). Psychosocial predictors of breast self-examination behavior among female students: An application of the health belief model using logistic regression. $B M C$ Public Health, 17(1), 1-9. https://doi.org/10.1186/s12889-017-4880-9

Ersin, F., Gözükara, F., Polat, P., Erçetin, G., \& Bozkurt, M. E. (2015). Determining the health beliefs and breast cancer fear levels of women regarding mammography. Turkish Journal of Medical Sciences, 45(4), 775-781. https://doi.org/10.3906/sag-1406-74

Erten, S. (2018). An Evaluation of Science Teacher Canditates 'Energy Saving Behavior Intention Based on the Theory of Planned Behaviour, 8(2), 123-149.

Farajzadegan, Z., Fathollahi-Dehkordi, F., Hematti, S., Sirous, R., Tavakoli, N., \& Rouzbahani, R. (2016). The 
transtheoretical model, health belief model, and breast cancer screening among Iranian women with a family history of breast cancer. Journal of Research in Medical Sciences, 21(8), 1-8. https://doi.org/10.4103/1735-1995.193513

Flores, R. T., Cano, M. Á., Correa-fernández, V., Field, C. A., Whitney, L., Strong, L. L., \& Field, C. A. (2018). Associations of Multiple Acculturation Domains With Smoking Status Among Latino Adults.

Garey, L., Peraza, N., Smit, T., Mayorga, N. A., Neighbors, C., Raines, A. M., Zvolensky, \& M. J. (2018). Sex Differences in Smoking Constructs and Abstinence: The Explanatory Role of Smoking Outcome Expectancies, 32(6), 660-669.

Geuens, M., \& De Pelsmacker, P. (2017). Planning and Conducting Experimental Advertising Research and Questionnaire Design. Journal of Advertising, 46(1), 83-100. https://doi.org/10.1080/00913367.2016.1225233

Gordon, R., Russell-Bennett, R., \& Lefebvre, R. C. (2016). Social marketing: the state of play and brokering the way forward. Journal of Marketing Management, 32(11-12), 1059-1082. https://doi.org/10.1080/0267257X.2016.1199156

Gupta, V. G., Gogia, A., Kumar, L., Sharma, A., Bakhshi, S., Sharma, M. C., \& Kumar, R. (2018). Combined Modality Treatment with "Dexamethasone, Methotrexate, Ifosfamide, L-Asparaginase, and Etoposide" Chemotherapy and Involved Field Radiotherapy for Early Stage Natural Killer/T Cell Lymphoma with Local Tumor Invasiveness: A Single-institution Stud. Indian Journal of Medical and Paediatric Oncology, 39(1), 67-72. https://doi.org/10.4103/ijmpo.ijmpo

Jamei, F., Ostovar, A., \& Javadzade, H. (2017). Predictors of exclusive breastfeeding among nulliparous Iranian mothers: Application of the theory of planned behavior. International Journal of Pediatrics, 5(3), 4457-4467. https://doi.org/10.22038/ijp.2016.20815.1748

Jezak, M. (2017). 2. Design-Based Research Methodology for Establishing the Common Theoretical Framework and the CLB/NCLC Scales. Language is the Key: The Canadian Language Benchmarks Model. Ottawa: University of Ottawa Press. Retrieved from

http://ezproxy.sunway.edu.my/login?url=http://search.ebscohost.com/login.aspx?direct=true\&db=edspmu\& AN=edspmu.MUSE9780776625843.7\&site=eds-live\&scope $=$ site

Kalolo, A., \& Kibusi, S. M. (2015). The influence of perceived behaviour control, attitude and empowerment on reported condom use and intention to use condoms among adolescents in rural Tanzania. Reproductive Health, 12(1), 1-10. https://doi.org/10.1186/s12978-015-0097-5

Ke, D., Yang, R., \& Jing, L. (2018). Combined diagnosis of breast cancer in the early stage by MRI and detection of gene expression. Experimental and Therapeutic Medicine, 16(2), 467-472. https://doi.org/10.3892/etm.2018.6242

Kirca, N., Tuzcu, A., \& Gozum, S. (2018). Breast Cancer Screening Behaviors of First Degree Relatives of Women Receiving Breast Cancer Treatment and the Affecting Factors. European Journal of Breast Health, 14(1), 23-28. https://doi.org/10.5152/ejbh.2017.3272

Kissal, A., Kartal, B., \& Cetin, O. (2017). The Determination of Knowledge, Applications and Health Beliefs of Third- and Fourth-Grade Nursing Students Regarding Breast Self-Exam. Journal of Breast Health, 13(1), 10-15. https://doi.org/10.5152/tjbh.2016.3207

Klehe, U. (2018). Using the Theory of Planned Behavior to Predict Faking in Selection Exercises Varying in Fidelity, 17, 155-160.

Koh, E., Choi, G.-Y., \& Cho, J. Y. (2016). Effectiveness of an Ongoing, Community-Based Breast Cancer Prevention Program for Korean American Women. Health \& Social Work, 41(1), 51-59. https://doi.org/10.1093/hsw/hlv086

Kopelowicz, A., Zarate, R., Wallace, C., Liberman, R., Lopez, S., \& Mintz, J. (2015). Using the Theory of Planned Behavior to Improve Treatment Adherence in Mexican Americans With Schizophrenia. $J$ Consult Clin Psychol, 83(5), 985-993. https://doi.org/10.1037/0022-006X.76.1.104

Kovacs, M. A., Palmer, A. M., Correa, J. B., \& Brandon, T. H. (2018). Smoking by young women with restrained eating following a food prime in the context of an alternative distractor. Experimental and Clinical Psychopharmacology, 26(2), 186-194. https://doi.org/10.1037/pha0000175

Lang, B. (2018). Using the theory of planned behaviour to explain the widespread consumption of counterfeit 
sports jerseys among American college students, 16(4), 315-332.

Leske, S., Strodl, E., \& Hou, X. Y. (2017). Predictors of dieting and non-dieting approaches among adults living in Australia. BMC Public Health, 17(1), 1-18. https://doi.org/10.1186/s12889-017-4131-0

Mar, C., Sam, J., \& Wilson, C. (2018). Breast cancer screening in British Columbia: A guide to discussion with patients. British Columbia Medical Journal, 60(1), 20-26.

Mattson, M., \& Basu, A. (2010). The message development tool: A case for effective operationalization of messaging in social marketing practice. Health Marketing Quarterly, 27(3), 275-290. https://doi.org/10.1080/07359683.2010.495305

Morrison, P. J., Hodgson, S. V, \& Haites, N. E. (2002). Familial breast and ovarian cancer. [electronic resource] : genetics, screening, and management. Cambridge, UK ; New York : Cambridge University Press, c2002. Retrieved from http://ezproxy.sunway.edu.my/login?url=http://search.ebscohost.com/login.aspx?direct=true\&db=cat01176a $\& \mathrm{AN}=$ thol.4261170\&site $=$ eds-live \&scope $=$ site

Mtenga, S. M., Exavery, A., Kakoko, D., \& Geubbels, E. (2015). Social cognitive determinants of HIV voluntary counselling and testing uptake among married individuals in Dar es Salaam Tanzania: Theory of Planned Behaviour (TPB). BMC Public Health, 15(1), 1-9. https://doi.org/10.1186/s12889-015-1545-4

Murphy, C. M., Rohsenow, D. J., Johnson, K. C., \& Wing, R. R. (2018). Smoking and weight loss among smokers with overweight and obesity in look AHEAD. Health Psychology, 37(5), 399-406. https://doi.org/10.1037/hea0000607

Mutua, K., Pertet, A. M., \& Otieno, C. (2017). Cultural factors associated with the intent to be screened for prostate cancer among adult men in a rural Kenyan community. BMC Public Health, 17(1), 1-9. https://doi.org/10.1186/s12889-017-4897-0

Narmawan, N., Syahrul, S., \& Erika, K. A. (2018). The Behavior Of Foot Care In Patients With Type 2 Diabetes Mellitus : Applying The Theory Of Planned Behaviour, 4(3), 129-137.

National cancer institute. (2018). Female Breast Cancer - Cancer Stat Facts. Retrieved September 21, 2018, from https://seer.cancer.gov/statfacts/html/breast.html

Ogbuanya, T. C., \& Chukwuedo, S. O. (2016). Journal of Work and Organizational Psychology. Journal of Work and Organizational Psychology, 33(3), 165-173. https://doi.org/10.1016/j.rpto.2017.09.003

Osina, S. (2017a). The Advancement of Nurses is the Advancement of Medicine: A Personal Experience from Israel. Asia Pac J Oncol Nurs, 4(2), 95-7. https://doi.org/10.4103/apjon.apjon

Osina, S. (2017b). The Advancement of Nurses is the Advancement of Medicine: A Personal Experience from Israel. Asia Pac J Oncol Nurs, 4(2), 95-7. https://doi.org/10.4103/apjon.apjon

Peechapol, C., Na-songkhla, J., Sujiva, S., \& Luangsodsai, A. (2018). Development of Smartphone Application Based on the Theory of Planned Behaviour to Enhance Self-Efficacy for Online Learning, 12(4), 135-151.

Pettey, D., \& Aubry, T. (2018). Psychiatric Rehabilitation Journal Tobacco Use and Smoking Behaviors of Individuals With a Serious Mental Illness Tobacco Use and Smoking Behaviors of Individuals With a Serious Mental Illness.

Radovanovic, M., \& Rus-Makovec, M. (2018). A temporal profile of pro-abstinence-oriented constructs from the modified theory of planed behavior in a slovenian clinical sample of treated alcoholics - An 18-year follow-up. Zdravstveno Varstvo, 57(1), 10-16. https://doi.org/10.2478/sjph-2018-0002

Rahmati-Najarkolaei, F., Pakpour, A. H., Saffari, M., Hosseini, M. S., Hajizadeh, F., Chen, H., \& Yekanineja, M. S. (2017). Determinants of lifestyle behavior in Iranian adults with prediabetes: Applying the theory of planned behavior. Archives of Iranian Medicine, 20(4), 198-204. https://doi.org/0172004/AIM.003

Rainey, L., van der Waal, D., Donnelly, L. S., Gareth Evans, D., Wengström, Y., \& Broeders, M. (2018). Women's decision-making regarding risk-stratified breast cancer screening and prevention from the perspective of international healthcare professionals. PLoS ONE, 13(6), 1-14. https://doi.org/10.1371/journal.pone.0197772

Santana, M. A. De, Mônica, J., Pereira, S., Lucimar, F., Lima, N. M. De, Sousa, F. N. De, \& Pinheiro, W. (2018). Breast cancer diagnosis based on mammary thermography and extreme learning machines, 34(February), 45-53. https://doi.org/10.1590/2446-4740.05217. 
Schillinger, D., Tran, J., \& Fine, S. (2018). Do low income youth of color see "the bigger picture" when discussing type 2 diabetes: A qualitative evaluation of a public health literacy campaign. International Journal of Environmental Research and Public Health, 15(5). https://doi.org/10.3390/ijerph15050840

Seow, A. N., Choong, Y. O., Moorthy, K., \& Chan, L. M. (2017). Intention to visit Malaysia for medical tourism using the antecedents of Theory of Planned Behaviour: A predictive model. International Journal of Tourism Research, 19(3), 383-393. https://doi.org/10.1002/jtr.2120

Setyowibowo, H., Purba, F. D., Hunfeld, J. A. M., Iskandarsyah, A., Sadarjoen, S. S., Passchier, J., \& Sijbrandij, M. (2018). Quality of life and health status of Indonesian women with breast cancer symptoms before the definitive diagnosis: A comparison with Indonesian women in general. PloS One, 13(7), e0200966. https://doi.org/https://dx.doi.org/10.1371/journal.pone.0200966

Smith, A., Mullooly, M., Murphy, L., Barron, T. I., \& Bennett, K. (2018). Associations between obesity , smoking and lymph node status at breast cancer diagnosis in the Prostate, Lung, Colorectal and Ovarian (PLCO ) Cancer Screening Trial. PLoS ONE, 13(8), e0202291.

https://doi.org/10.1371/journal.pone.0202291

Smith, M. A., Conway-Phillips, R., \& Francois-Blue, T. (2016). Sisters saving lives: Instituting a protocol to address breast cancer disparities. Clinical Journal of Oncology Nursing, 20(4), 427-432. https://doi.org/10.1188/16.CJON.427-432

Spotswood, F., French, J., Tapp, A., \& Stead, M. (2012). Some reasonable but uncomfortable questions about social marketing. Journal of Social Marketing, 2(3), 163-175. https://doi.org/10.1108/20426761211265168

Sun, L., Legood, R., Sadique, Z., dos-Santos-Silva, I., \& Yang, L. (2018). Cost-effectiveness of risk-based breast cancer screening programme, China. Bulletin of the World Health Organization, 96(8), 568-577. https://doi.org/10.2471/BLT.18.207944

Susan, K. (2015). Prevention and Risk Reduction. Dr. Susan Love's Breast Book. Da Capo. Retrieved from http://ezproxy.sunway.edu.my/login?url=http://search.ebscohost.com/login.aspx?direct=true\&db=edscra\&A $\mathrm{N}=$ edscra.20849058\&site=eds-live \&scope $=$ site

Tarkowska, M., Mrotek, I. G., \& Gastecka, A. (2017). Evaluating knowledge of young women regarding breast cancer prevention, 7(9), 22-32.

Torbaghan, A. E., Farmanfarma, K. K., Moghaddam, A. A., \& Zarei, Z. (2014). Improving Breast Cancer Preventive Behavior among Female Medical Staff: The Use of Educational Intervention based on Health Belief Model. Malays J Med Sci, 21(5), 44-50. Retrieved from http://www.ncbi.nlm.nih.gov/pubmed/25977633

Van den Berk-Clark, C., Secrest, S., Walls, J., Hallberg, E., Lustman, P. J., Schneider, F. D., \& Scherrer, J. F. (2018). Association between posttraumatic stress disorder and lack of exercise, poor diet, obesity, and co-occuring smoking: A systematic review and meta-analysis. Health Psychology, 37(5), 407-416. https://doi.org/10.1037/hea0000593

Venturini, R. (2016). Social marketing and big social change: personal social marketing insights from a complex system obesity prevention intervention. Journal of Marketing Management, 32(11-12), 1190-1199. https://doi.org/10.1080/0267257X.2016.1191240

Wang, W. L., Hsu, S. Der, Wang, J. H., Huang, L. C., \& Hsu, W. L. (2014). Survey of breast cancer mammography screening behaviors in Eastern Taiwan based on a health belief model. Kaohsiung Journal of Medical Sciences, 30(8), 422-427. https://doi.org/10.1016/j.kjms.2014.04.007

Yilmaz, M., \& Durmus, T. (2016). Health Beliefs and Breast Cancer Screening Behavior among a Group of Female Health Professionals in Turkey. Journal of Breast Health, 12(1), 18-24. https://doi.org/10.5152/tjbh.2015.2715

Zhang, Y. (2015). Using a Mixed Design Study To Develop a Breast Screening Intervention Among Chinese Women in the Uk.

\section{Copyrights}

Copyright for this article is retained by the author(s), with first publication rights granted to the journal.

This is an open-access article distributed under the terms and conditions of the Creative Commons Attribution license (http://creativecommons.org/licenses/by/4.0/). 